\title{
Case Series of Clinical Findings of Multi-System Inflammatory Syndrome in Children in Contrast to Kawasaki Disease
}

\author{
Htay H. Aung ${ }^{1}$, Oksana Nulman ${ }^{1}$, Iram Nadroo ${ }^{1}$, Manoj Chhabra ${ }^{1}$ \\ 1. Pediatric Medicine, New York-Presbyterian Brooklyn Methodist Hospital, Brooklyn, USA
}

Corresponding author: Iram Nadroo, ian9002@nyp.org

\begin{abstract}
Several months into the coronavirus disease 2019 (COVID-19) pandemic, there is growing concern over an increase in the incidence of severe acute respiratory syndrome coronavirus 2 (SARS-CoV-2)-linked Kawasaki-like disease in the pediatric population. The pediatric patients presented to the emergency room with impending shock in the setting of an atypical Kawasaki picture. On May 14, 2020, the CDC Health Alert Network released a case definition for this evolving syndrome and named it multi-system inflammatory syndrome in children (MIS-C). We report three cases of MIS-C associated with SAR-COV2 who presented to our emergency room. Persistent fever was present in all three patients and mucocutaneous and gastrointestinal symptoms were the most common associations. All three patients were found to have antibodies to COVID-19. MIS-C is a similar but distinct entity as compared to Kawasaki disease. High inflammatory markers are supportive of the diagnosis, and cardiac evaluation is crucial in MIS-C. High suspicion for the diagnosis and low threshold for workup will prevent delayed treatment.
\end{abstract}

Review began 06/22/2021 Review ended 07/08/2021 Published 07/17/2021

\section{() Copyright 2021}

Aung et al. This is an open access article distributed under the terms of the Creative Commons Attribution License CC-BY 4.0., which permits unrestricted use, distribution, and reproduction in any medium, provided the original author and source are credited.
Categories: Cardiology, Pediatrics, Infectious Disease

Keywords: covid-19, kawasaki disease, sars-cov-2, pediatric multisystem inflammatory disease, covid-19 related, pediatric, coronavirus

\section{Introduction}

While the rate of coronavirus disease 2019 (COVID-19) infections in adults appears to be decreasing, there is growing concern over an increase in the incidence of Kawasaki-like disease linked to severe acute respiratory syndrome coronavirus 2 (SARS-CoV-2) infection in the pediatric population [1]. We are learning about the clinical manifestations of COVID-19 in children, some of whom are asymptomatic while others have a fever with respiratory and gastrointestinal symptoms. These symptoms usually appear to be mild and tend to selfresolve without any apparent complications [2]. However, a small subset of pediatric patients who were exposed to SARS-CoV-2 or contracted COVID-19 are presenting with Kawasaki-like features, complicated by multi-system involvement, including the cardiac system [3].

The CDC announced a case definition for multi-system inflammatory syndrome in children (MIS-C) on May 14, 2020. The timing of MIS-C suggests an immunological phenomenon similar to Kawasaki disease (KD) [4]. $\mathrm{KD}$ is an acute self-limiting vasculitis with a predilection for the coronary arteries that affects previously healthy children [5]. Echocardiography is indispensable in diagnosing coronary artery vasculitis and monitoring its complications.

It is still unclear whether MIS-C has a predilection for coronary arteries like KD does. According to recently published articles, in cases of SARS-CoV2-linked MIS-C, baseline EKGs were non-specific and the most common echocardiographic finding was ventricular dysfunction, which could lead to shock [6]. It has become increasingly clear that SARS-CoV2-linked MIS-C can be a serious condition, requiring immediate life-saving intervention [7]. In this review, we present the clinical manifestations and various echocardiographic findings associated with MIS-C in our patients, with the goal of identifying both common and specific findings, thereby helping clinicians identify and manage this newly evolving syndrome.

\section{Case Presentation}

\section{Case 1}

A previously healthy five-year-old male presented to our emergency department (ED) with the chief complaint of five days of fever [maximum temperature (Tmax) of $40^{\circ} \mathrm{C}$ ] associated with vomiting, sporadic watery diarrhea, resolving red puffy eyes, and rashes over his left lower leg. His parents also reported a mild cough during the first few days of illness. They noticed fast and noisy breathing on day five of illness, and this prompted them to bring the patient into the ED. Two weeks prior to the onset of symptoms, the patient's father was noted to be SARS-CoV-2 positive. On physical examination, the patient was alert and well-appearing but febrile at $38.1^{\circ} \mathrm{C}$, tachycardic at $162 \mathrm{bpm}$, and mildly tachypneic at $30 \mathrm{bpm}$ without any chest wall retractions. His blood pressure was within normal limits. He was also noted to have significant 


\section{Cureus}

bilateral conjunctivitis as well as a small oral ulcer.

His complete blood count (CBC) was significant for anemia with a hemoglobin of $8.9 \mathrm{mg} / \mathrm{dL}$; white blood cell (WBC) count was at the upper limit of normal with associated neutrophilia and lymphopenia; and normal platelets. Liver enzymes and serum creatinine were within normal limits but there was hyponatremia (Na $130 \mathrm{mmol} / \mathrm{L}$ ) and hypoalbuminemia (albumin $3.1 \mathrm{~g} / \mathrm{dl}$ ). Inflammatory markers erythrocyte sedimentation rate (ESR) and C-reactive protein (CRP) were elevated at $123 \mathrm{~mm} / \mathrm{hr}$ and $322 \mathrm{mg} / \mathrm{L}$. Given persistent tachycardia, Troponin I levels were obtained and were noted to be high as well $(.081 \mathrm{ng} / \mathrm{ml})$. His blood cultures remained negative. While he was noted to be negative for SARS-COV-2 reverse transcriptionpolymerase chain reaction (RT-PCR), he was positive on antibody testing. Chest X-ray (CXR) revealed streaky perihilar airspace opacity and mild peribronchial thickening, but no focal consolidations (Figure 1). The cardiac shadow was normal on CXR.

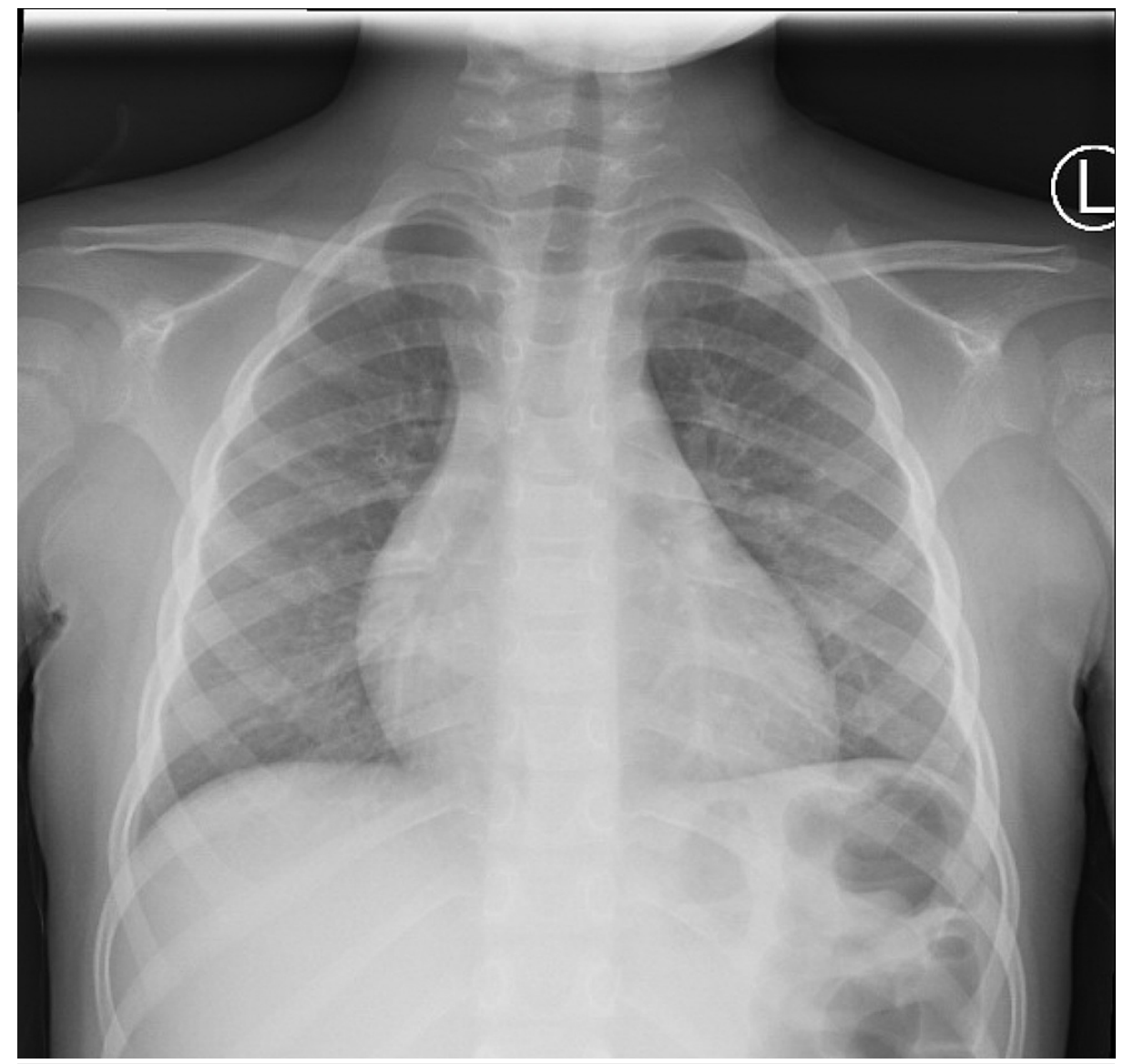

\section{FIGURE 1: CXR showing streaky perihilar airspace opacity and mild peribronchial thickening}

EKG and echocardiogram (Echo) revealed non-specific abnormal findings. EKG showed sinus tachycardia, right atrium enlargement, and ST/T wave changes (Figure 2). 


\section{Cureus}

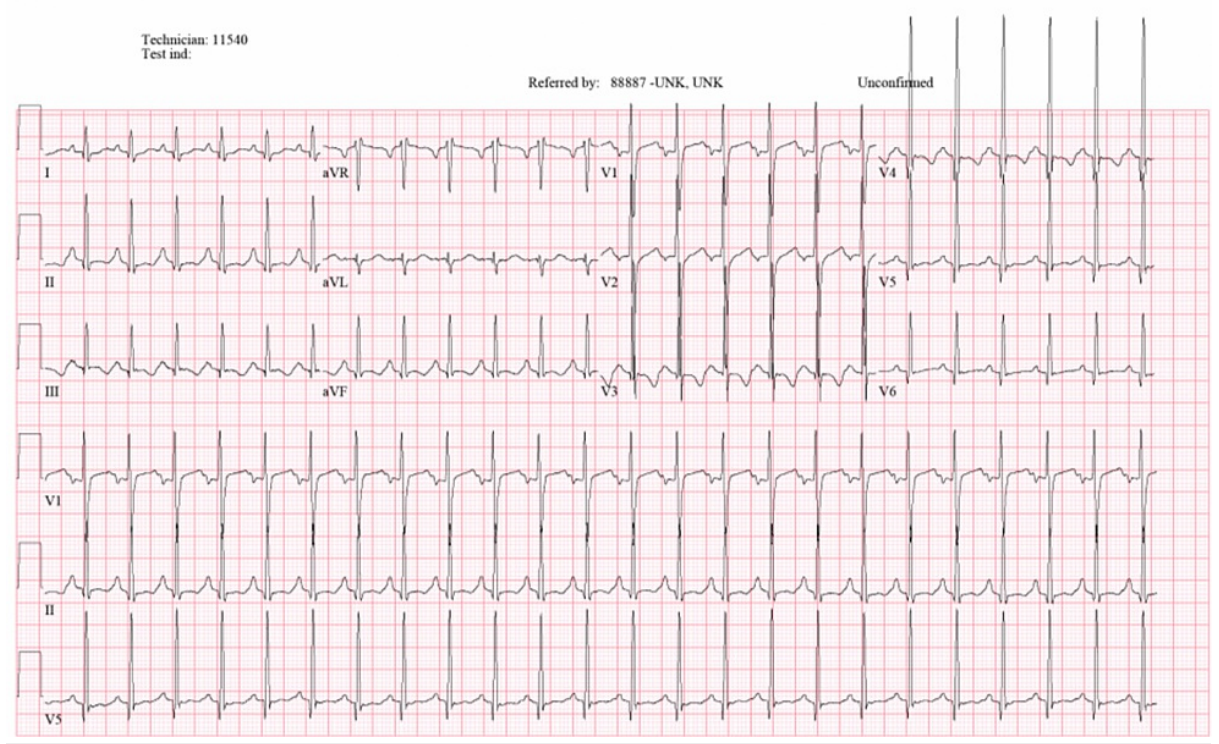

FIGURE 2: EKG showing sinus tachycardia, right atrium enlargement, and $S T / T$ wave changes

Echo showed mild mitral regurgitation (MR) and tricuspid regurgitation (TR) with poor cardiac function (ejection fraction [EF] of 21\%) (Figures 3-4). The remainder of the cardiac anatomy, including the coronary arteries, was unremarkable.

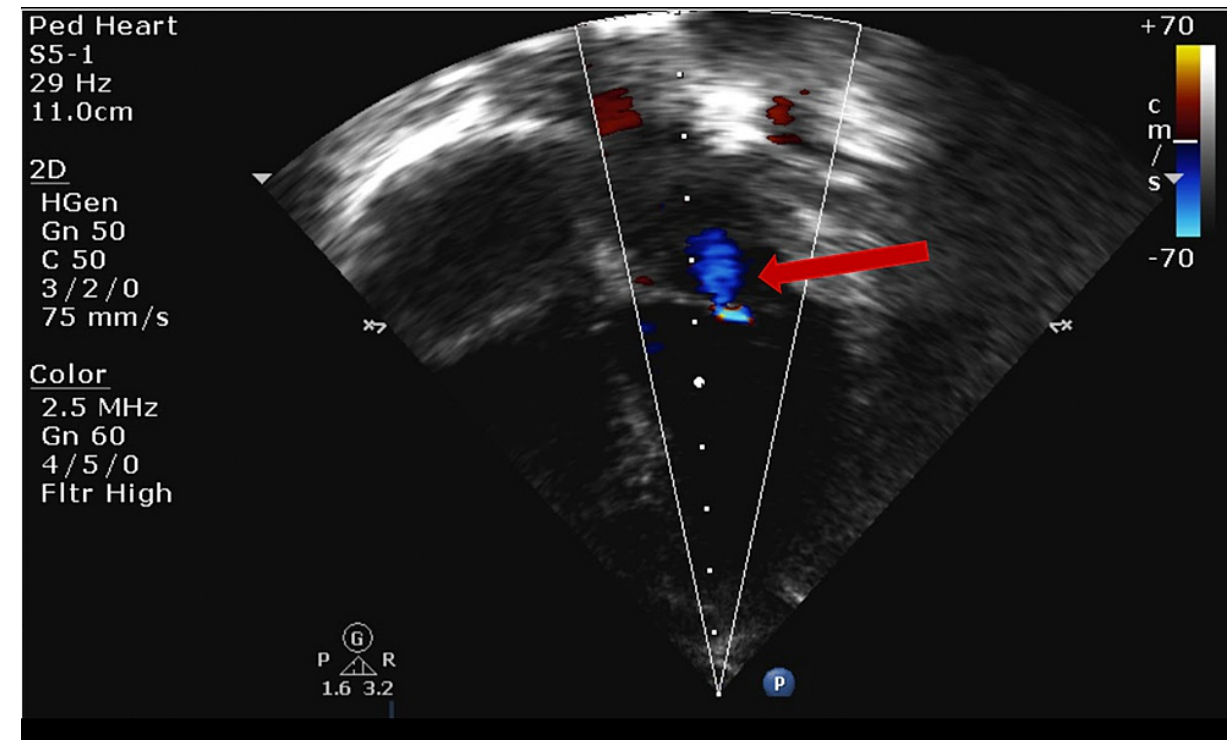

FIGURE 3: Transthoracic echocardiogram (TTE) apical four-chamber view showing mild mitral regurgitation 


\section{Cureus}

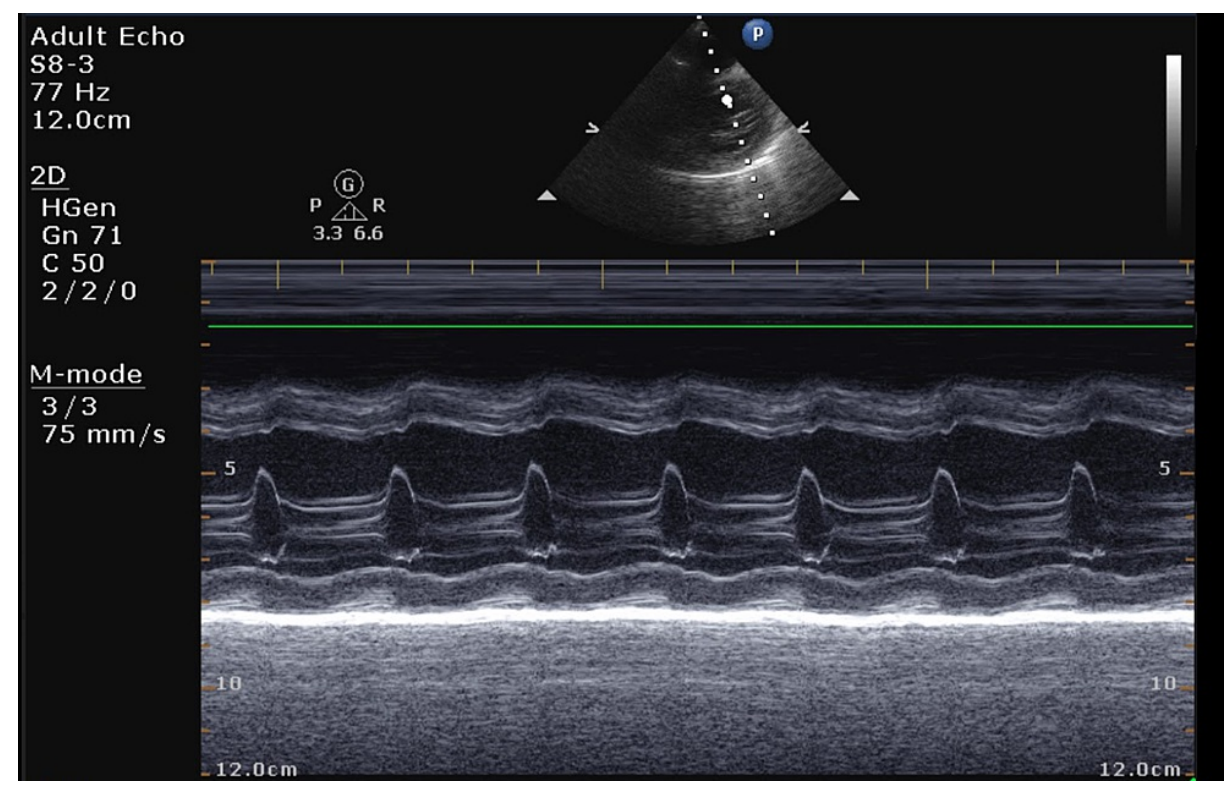

FIGURE 4: Transthoracic echocardiogram (TTE) parasternal short-axis M mode showing decreased left ventricular systolic function

\section{Case 2}

A 15-year-old female with significant past medical history (PMH) of poorly controlled asthma presented to the ED with four days of fever $\left(\operatorname{Tmax} 38.9^{\circ} \mathrm{C}\right)$ with intermittent frontal headache, pleuritic central chest pain, and epigastric pain. She denied any respiratory symptoms. There were no known sick contacts. In the ED, she was febrile at $38.4^{\circ} \mathrm{C}$ and tachycardic at $136 \mathrm{bpm}$. The remainder of her vital signs were within normal limits. She was noted to have bilateral conjunctivitis and macular palmar rashes. Aside from the tachycardia, her cardiac, chest, and abdominal examinations were within normal limits.

CBC was unremarkable except for neutrophilia and lymphopenia. Liver function tests, renal function tests, and electrolytes were within the normal limit. CRP and ferritin levels were elevated at $216 \mathrm{mg} / \mathrm{L}$ and 340 $\mathrm{ng} / \mathrm{ml}$, respectively, as were fibrinogen and D-dimer levels at $>700 \mathrm{mg} / \mathrm{dl}$ and $1423 \mathrm{ng} / \mathrm{ml}$, respectively. Pro Btype natriuretic peptide (Pro-BNP) was also found to be significantly elevated at 6000 s while other cardiac markers, such as Troponin-I and CK-MB, were normal. Blood culture and urine culture remained negative. This patient was also noted to be SARSCoV2 negative on PCR but had a positive antibody test. CXR revealed mild hyperinflation with prominent interstitial markings (Figure 5). 


\section{Cureus}

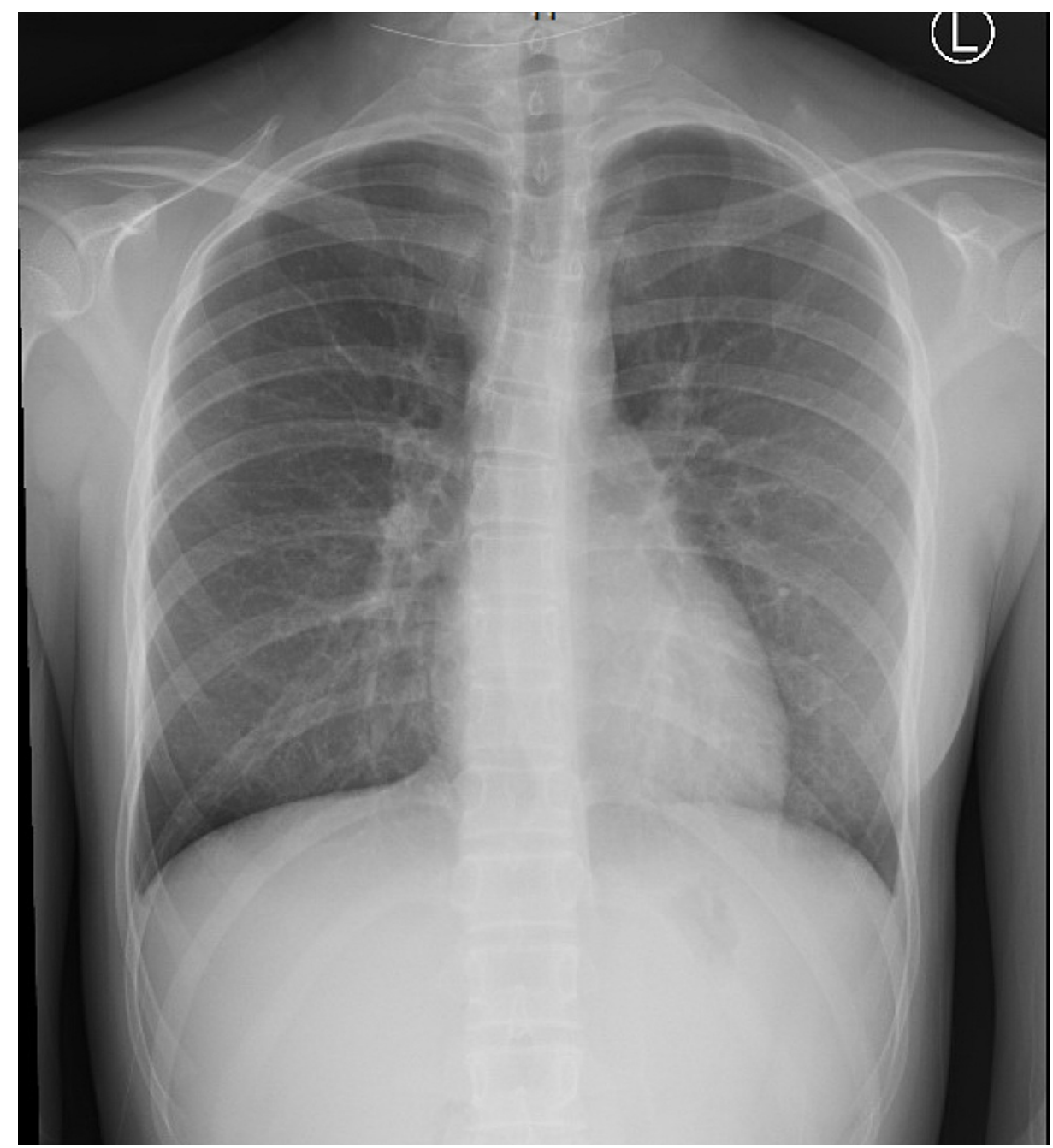

FIGURE 5: CXR showing mild hyperinflation with prominent interstitial markings

CXR: chest X-ray

EKG showed sinus tachycardia and echo findings were significant for mild MR, mild pericardial effusion, and thickening of left ventricular (LV) posterior wall with poor function (EF 23-25\%) (Figures 6-7). Coronaries were noted to be normal. 


\section{Cureus}

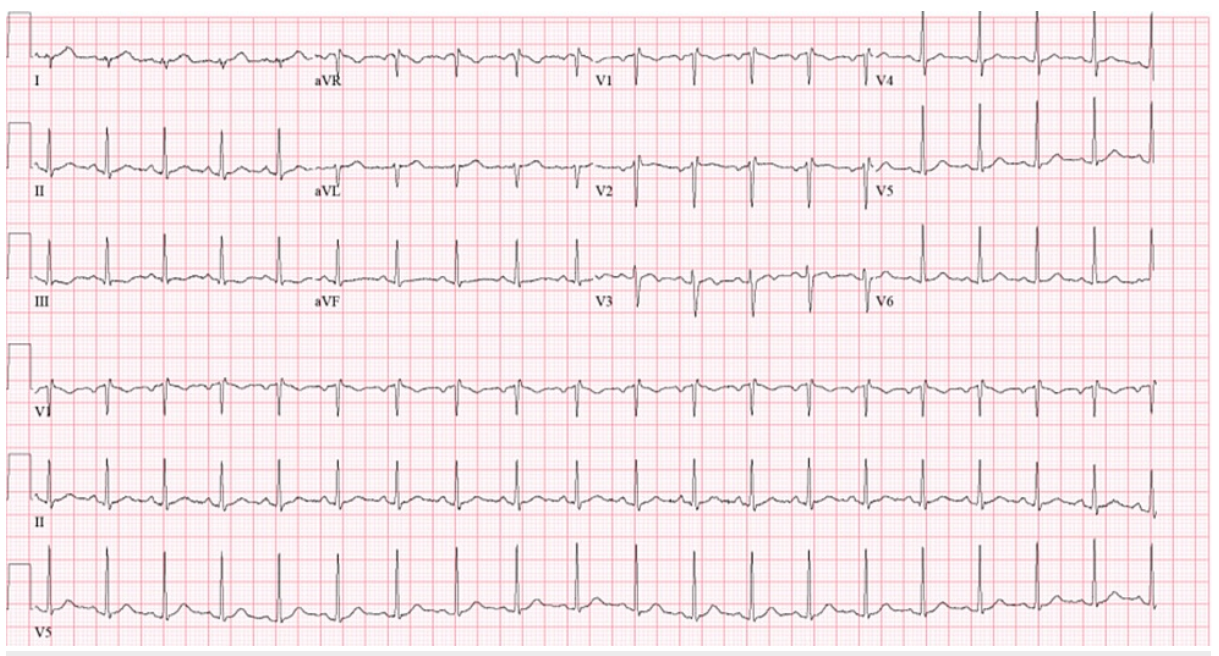

FIGURE 6: EKG showing sinus tachycardia

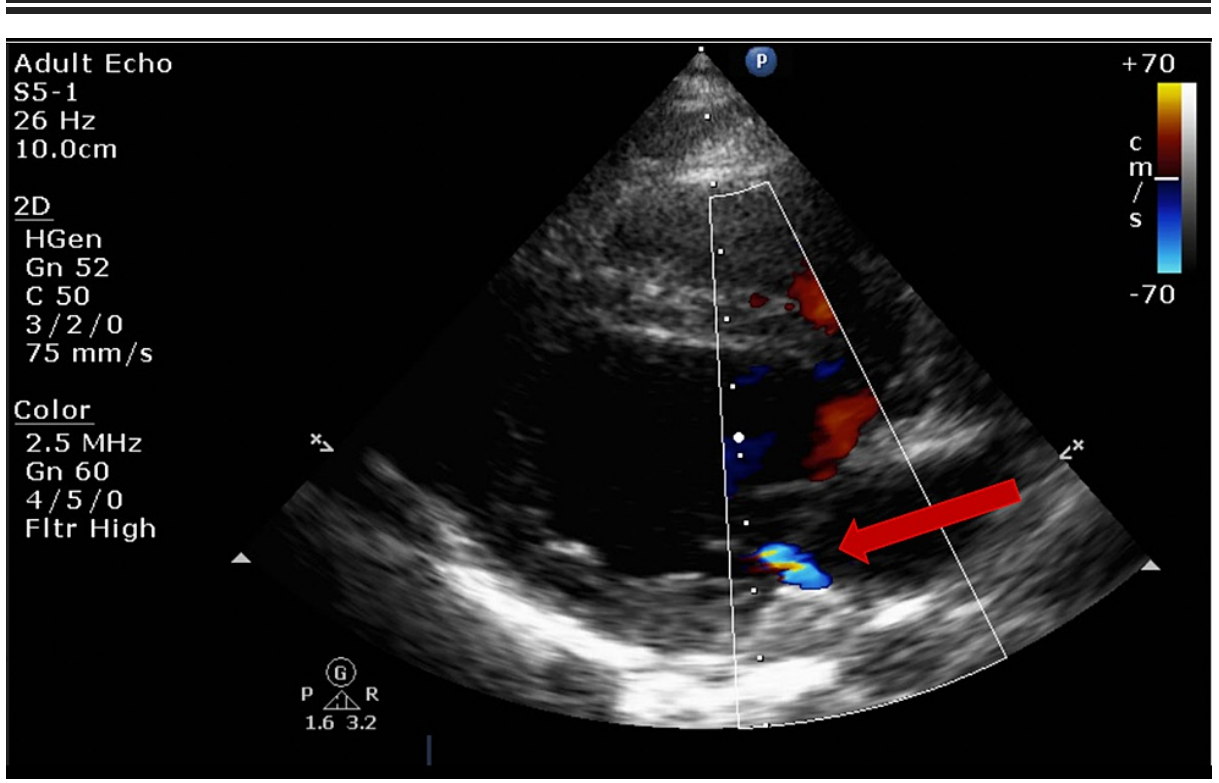

FIGURE 7: Transthoracic echocardiogram (TTE) parasternal long-axis view showing mild mitral regurgitation

\section{Case 3}

A six-year-old male, with no $\mathrm{PMH}$, presented with fever for six days (Tmax $39.6^{\circ} \mathrm{C}$ ), associated with generalized abdominal pain, followed by vomiting, facial rash, and itchy eyes. The parents also reported a mild cough and some rhinorrhea. The patient's uncle was noted to be SARs-CoV-2 positive two months ago. The patient's vital signs were within normal limits on presentation except for tachycardia at $123 \mathrm{bpm}$ with no associated fever. On physical examination, he was noted to be well-appearing, with bilateral conjunctivitis, chapped lips, and generalized fine papular rash. Chest and abdomen examinations were unremarkable.

CBC, basic metabolic panel (BMP), and liver function tests were within normal limits. CRP, ESR, and D-dimer were increased (CRP $23.3 \mathrm{mg} / \mathrm{dl}$, ESR $57 \mathrm{~mm} / \mathrm{hr}$, D-dimer $341.5 \mathrm{ng} / \mathrm{ml}$ ) but other inflammatory markers (ferritin, lactate dehydrogenase (LDH), and procalcitonin) and cardiac markers (CK-MB, Troponin I, and Pro BNP) were normal. Blood culture, urine culture, and throat culture remained negative. CXR and EKG were unremarkable (Figures 8-9). 


\section{Cureus}

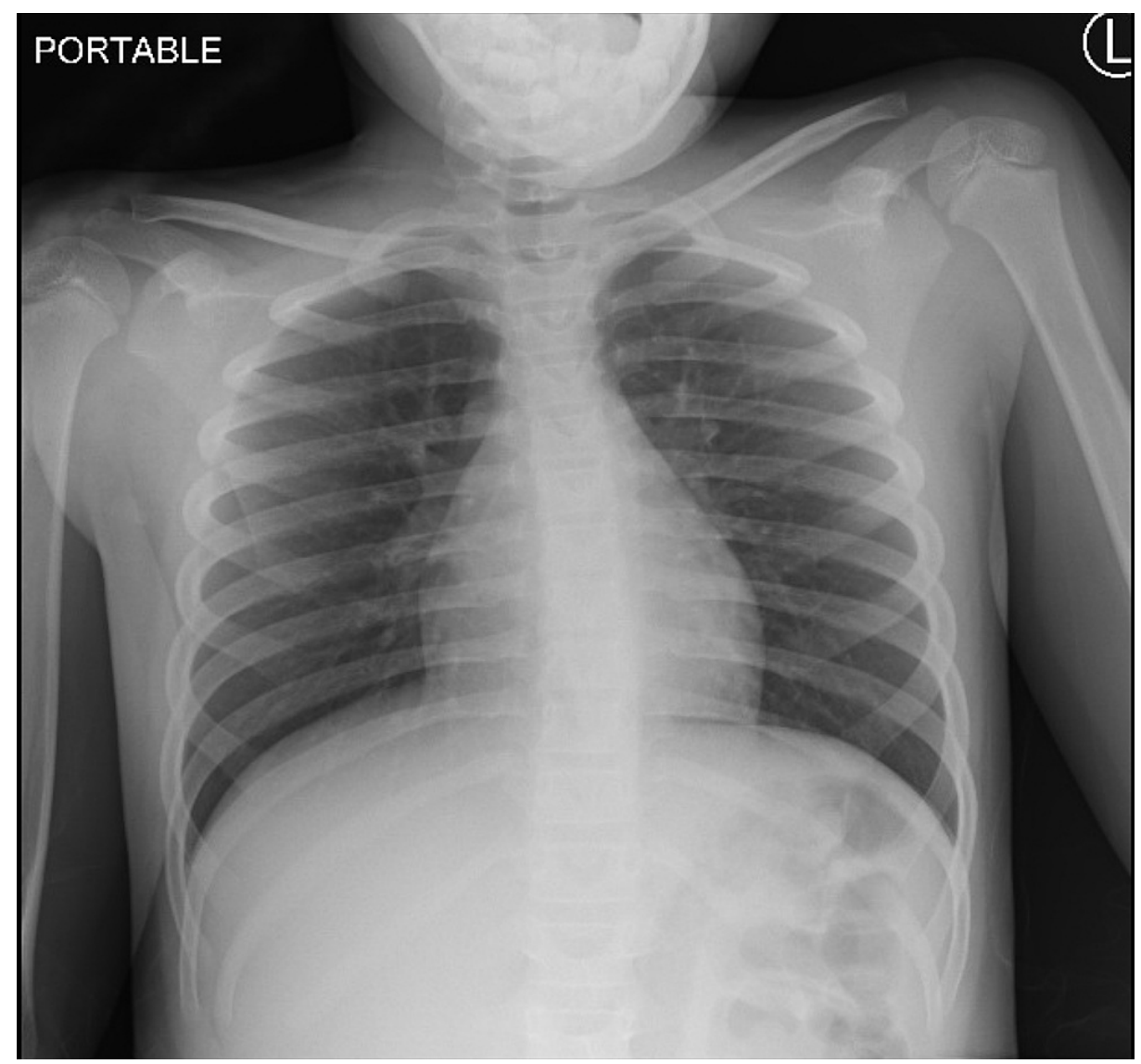

\section{FIGURE 8: Normal CXR}

CXR: chest X-ray

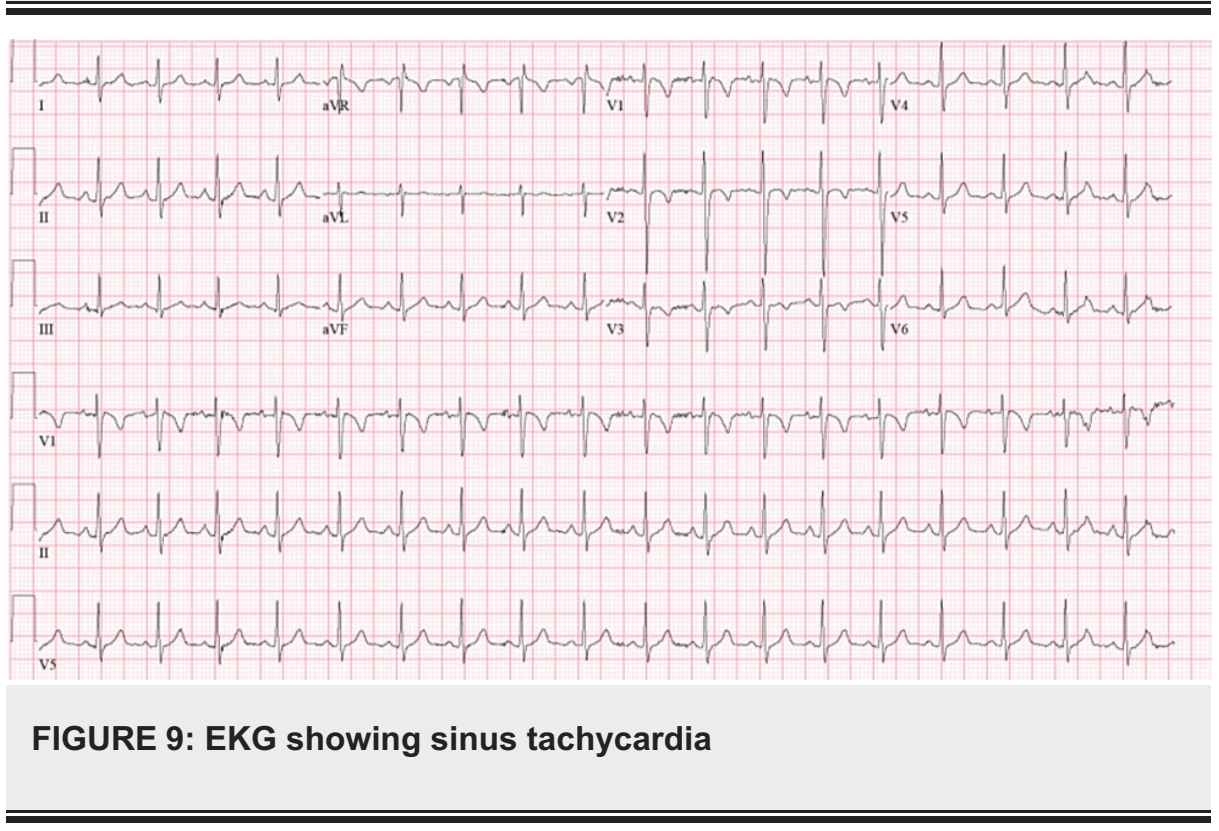

However, a trivial pericardial effusion and prominent left coronary were appreciated on echo (Figures 10-11). 


\section{Cureus}

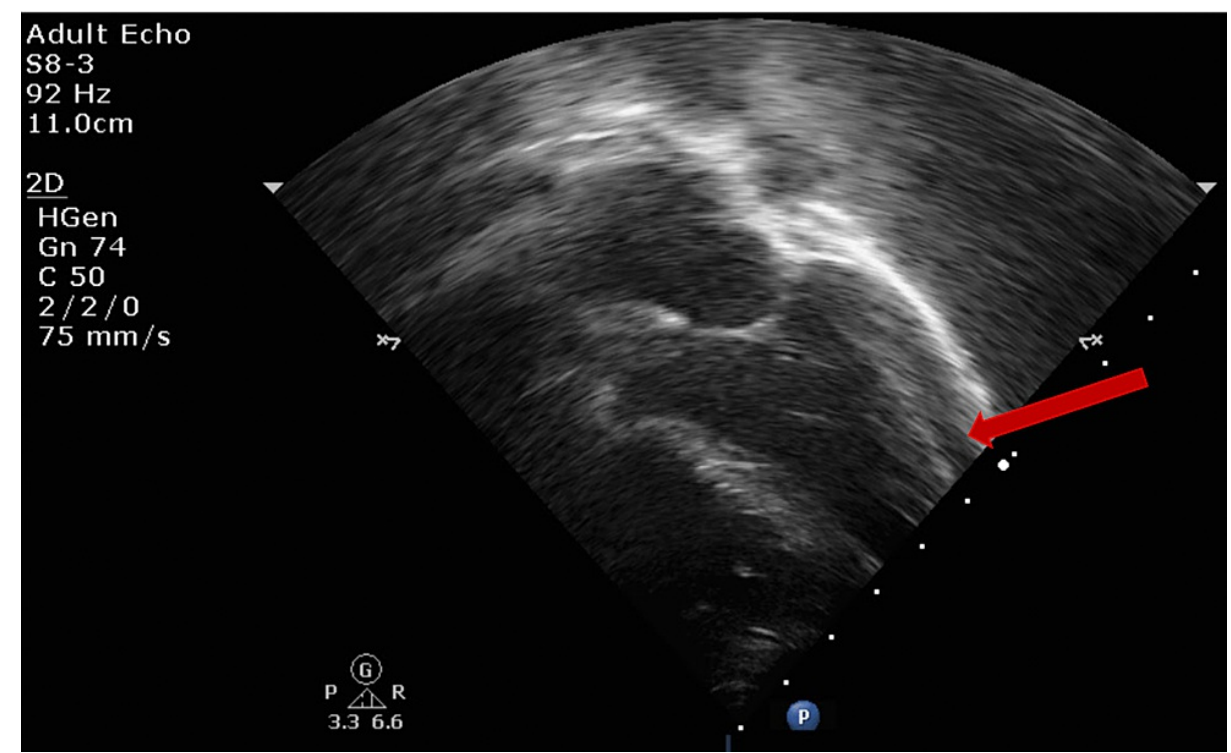

FIGURE 10: Transthoracic echocardiogram (TTE) subxiphoid short-axis view showing trivial pericardial effusion

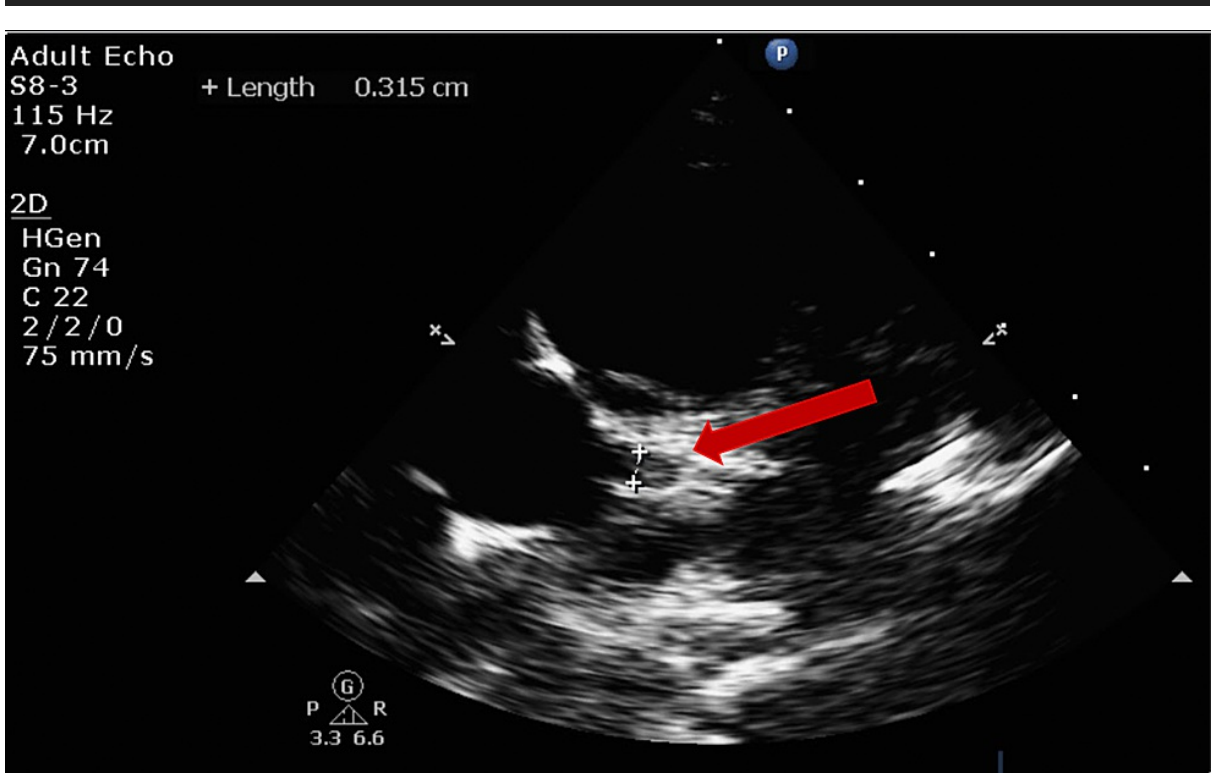

FIGURE 11: Transthoracic echocardiogram (TTE) showing left coronary prominence

EF was noted to be $69 \%$, and the remainder of the cardiac anatomy was noted to be within normal limits. This patient was also noted to be SARS-CoV-2 negative on PCR but had a positive antibody test.

\section{Discussion}

At the beginning of the COVID-19 pandemic, we thought that pediatric patients were less vulnerable to the virus as compared to adults [2]. Several months into the pandemic, we started seeing a newly evolving inflammatory syndrome in pediatric patients who were exposed to SARS-CoV-2. The New York State Department of Health has issued a statement that as of May 5, 2020, "sixty-four suspected pediatric clinical cases compatible with multi-system inflammatory syndrome associated with COVID-19 have been reported in children in New York State hospitals [8].

On May 14, 2020, the CDC Health Alert Network released a case definition for MIS-C [9]. The health advisory provided the following criteria, all of which need to be met to qualify as MIS-C: an individual younger than 21 years; presenting with fever; $\geqslant 38^{\circ} \mathrm{C}$ for $\geqslant 24$ hours, or report of subjective fever lasting $\geqslant 24$ hours; elevated 
inflammatory markers; clinically severe illness requiring hospitalization, with multiorgan ( $\geqslant 2$ ) involvement; patients should not have an alternative diagnosis to explain their illness; patients should be positive for current or recent SARS-CoV-2 infection by RT-PCR, serology, or antigen test; or COVID-19 exposure within the four weeks before the onset of symptoms.

As of March 1, 2021, there was a total of 2617 MIS-C cases meeting the above criteria and 33 MIS-C deaths meeting the case definition. The question of why some children develop MIS-C after COVID-19 or after contact with someone who has COVID-19 and some do not remains unanswered [10].

We reported three cases of MIS-C. Persistent fever was seen in all three patients. Fever is commonly associated with mucocutaneous manifestation such as various forms of rashes, conjunctivitis, and oral mucosa ulcer. While the fever and mucocutaneous findings in MIS-C are similar to those of Kawasaki disease, gastrointestinal symptoms, such as anorexia, nausea, vomiting, diarrhea, and abdominal pain, favor the diagnosis more toward MIS-C than KD. Furthermore, respiratory symptoms that are commonly seen in adults are less prominent in children.

Inflammatory markers, including, ESR, CRP, ferritin, fibrinogen, and D-dimer, were high in all three patients (Table 1). Cardiac markers, such as Troponin I and BNP, were significantly high only in Patient 1.

Patient 1 has been exposed to SARS-CoV-2 2 weeks prior to presentation and Patient 3 had confirmed exposure two months prior to presentation. All of them were noted to be SARS-CoV-2 negative on PCR but had a positive antibody test, which proposed a possible immune-mediated inflammatory response to the COVID-19 virus.

Common abnormal vital signs seen in most patients, apart from fever, were tachycardia with borderline blood pressure. Fluids have to be cautiously given due to the possible association of viral-induced myocarditis. That is when cardiac imaging and lab markers come into play in management.

Echocardiogram findings were variable in all three patients, including impaired ventricular function, mild/trivial pericardial effusion, prominent coronary arteries, and mild functional heart valve abnormalities such as mitral regurgitation and tricuspid regurgitation. Unlike KD, abnormal echo findings were seen early in the course of the disease in MIS-C and severe cardiac involvement like ventricular dysfunction can lead to death if left untreated or delay in treatment. All three patients were admitted to the in-patient unit for close cardiopulmonary monitoring due to the concern for rapid hemodynamic decompensation and treated with IVIG (IV immunoglobulin). Echo(es) were repeated before discharge and during the outpatient follow-up and all abnormal findings were resolved.

Ever since the first patient, physicians in our institution were setting a low threshold for workup of MIS-C in pediatric patients who come in with persistent fever, various rashes, and gastrointestinal (GI) symptoms in order to diagnose and treat early. Workup includes basic labs, inflammatory markers, cardiac markers, SARSCOV-2 PCR, and antibody testing (Table 1). An echocardiogram should be performed as soon as available; findings are variable but poor ventricular function and pericardial effusion are common. Coronary artery prominences are noted as in $\mathrm{KD}$ as well.

\begin{tabular}{|c|c|c|c|}
\hline & Patient 1 & Patient 2 & Patient 3 \\
\hline \multicolumn{4}{|l|}{ СВC } \\
\hline $\mathrm{Hb}(\mathrm{g} / \mathrm{dl})$ & 8.9 & 13.9 & 11.6 \\
\hline 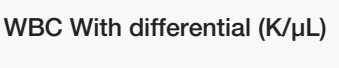 & $\begin{array}{l}15.2 \text { With Neutrophils }-85.2 \% \text {, } \\
\text { Lymphocytes }-9.2 \%\end{array}$ & $\begin{array}{l}11.9 \text { With Neutrophils - } 92.4 \% \text {, } \\
\text { Lymphocytes - } 3 \%\end{array}$ & $\begin{array}{l}5.7 \text { With Neutrophils - 60.6\%, } \\
\text { Lymphocytes - } 31.5 \%\end{array}$ \\
\hline Platelets $(\mathrm{K} / \mu \mathrm{L})$ & 233 & 213 & 268 \\
\hline \multicolumn{4}{|c|}{ Renal Function With Electrolytes } \\
\hline BUN (mg/dl) & 14 & 15 & 11 \\
\hline Creatinine (mg/dl) & 0.42 & 0.62 & 0.51 \\
\hline $\mathrm{Na}+(\mathrm{mmol} / \mathrm{L})$ & 130 & 135 & 139 \\
\hline Other Electrolytes & Normal & Normal & Normal \\
\hline \multicolumn{4}{|c|}{ Liver Function Test With Proteins } \\
\hline AST (unit/L) & 33 & 29 & 29 \\
\hline c (unit/L) & 56 & 38 & 34 \\
\hline
\end{tabular}




\section{Cureus}

\begin{tabular}{|c|c|c|c|}
\hline Total Protein (g/dl) & 7.3 & 6.7 & 7.8 \\
\hline $\begin{array}{l}\text { Albumin (g/dl) [reference: } \\
3.4-5]\end{array}$ & 3.1 & 3.3 & 3.6 \\
\hline \multicolumn{4}{|l|}{ Inflammatory Markers } \\
\hline $\begin{array}{l}\text { ESR (mm/HR) [reference: 3- } \\
13]\end{array}$ & 123 & - & 57 \\
\hline CRP $(\mathrm{mg} / \mathrm{L})$ [reference: $=<3]$ & 322 & 216 & 23.3 \\
\hline $\begin{array}{l}\text { Ferritin (ng/ml) [reference: 8- } \\
\text { 252] }\end{array}$ & 865.6 & 340.8 & 46.8 \\
\hline \multicolumn{4}{|l|}{ Coagulation Studies } \\
\hline $\begin{array}{l}\text { PT (INR) (sec) [reference: } \\
9.6-12.7]\end{array}$ & 14.4/1.1 & 17.1/1.4 & 13.3/1.16 \\
\hline $\begin{array}{l}\text { aPTT (sec) [reference: 25- } \\
\text { 35.6] }\end{array}$ & 30.5 & 38.5 & 32.9 \\
\hline $\begin{array}{l}\text { Fibrinogen }(\mathrm{mg} / \mathrm{dll}) \\
\text { [reference: } 263-623]\end{array}$ & 598 & $>700$ & 546 \\
\hline $\begin{array}{l}\text { D-dimer (ng/ml) [reference: } \\
\text { 30-230] }\end{array}$ & 4350 & 1423 & 341.5 \\
\hline \multicolumn{4}{|l|}{ Cardiac Markers } \\
\hline $\begin{array}{l}\text { Troponin I (ng/ml) } \\
\text { [reference: = }\end{array}$ & .081 & .015 & .019 \\
\hline $\begin{array}{l}\text { Pro-BNP (pg/ml) [reference: } \\
=<125 \text { ] }\end{array}$ & 27768 & 6278 & 78 \\
\hline $\begin{array}{l}\text { LDH (unit/L) [reference: 84- } \\
246]\end{array}$ & 266 & 356 & 210 \\
\hline \multicolumn{4}{|l|}{ SARS-COV-2 Assays } \\
\hline $\begin{array}{l}\text { SARS-COV-2 RT-PCR } \\
\text { (Nasopharyngeal Swab) }\end{array}$ & Negative & Negative & Negative \\
\hline Antibody Serology & Positive & Positive & Positive \\
\hline \multicolumn{4}{|l|}{ Microbiology } \\
\hline Blood Culture & Negative & - & Negative \\
\hline Urine Culture & - & & Negative \\
\hline
\end{tabular}

\section{TABLE 1: Comparison of the laboratory values of the presented cases}

BUN: blood urea nitrogen; AST: aspartate aminotransferase; ALT: alanine transaminase; ESR: erythrocyte sedimentation rate; CRP: C-reactive protein; PT: prothrombin time; INR: international normalized ratio; aPTT: activated partial thromboplastin time; Pro-BNP: pro-B-type natriuretic peptide; LDH: lactate dehydrogenase; SARS-COV-2: severe acute respiratory syndrome coronavirus 2; RT-PCR: reverse transcription-polymerase chain reaction

\section{Conclusions}

In conclusion, MIS-C is a similar but distinct entity as compared to KD. A history of exposure to COVID-19 is important although not universally available. Persistent fever with high inflammatory markers are seen in almost all patients. However, cardiac markers, such as BNP, cannot be relied on as the marker of this syndrome. The echocardiogram findings are variable but focus on ventricular function and prominence of coronary arteries. Mild pericardial effusion is a non-specific but common finding in MIS-C. A multidisciplinary approach, including a cardiologist, intensivist, and infectious disease specialist, should be involved in individualized management. We hope our cases contribute to the literature pool. Ultimately, a complete understanding of the pathophysiology and evidence-based management guidelines awaits further studies. 


\section{Additional Information}

\section{Disclosures}

Human subjects: Consent was obtained or waived by all participants in this study. Conflicts of interest: In compliance with the ICMJE uniform disclosure form, all authors declare the following: Payment/services info: All authors have declared that no financial support was received from any organization for the submitted work. Financial relationships: All authors have declared that they have no financial relationships at present or within the previous three years with any organizations that might have an interest in the submitted work. Other relationships: All authors have declared that there are no other relationships or activities that could appear to have influenced the submitted work.

\section{References}

1. Mahase E: Covid-19: concerns grow over inflammatory syndrome emerging in children . BMJ. 2020, 369:m1710. 10.1136/bmj.m1710

2. Zhu L, Lu X, Chen L: Possible causes for decreased susceptibility of children to coronavirus . Pediatr Res. 2020, 88:342. 10.1038/s41390-020-0892-8

3. Riphagen S, Gomez X, Gonzalez-Martinez C, Wilkinson N, Theocharis P: Hyperinflammatory shock in children during COVID-19 pandemic. Lancet. 2020, 395:1607-8.

4. Loke YH, Berul CI, Harahsheh AS: Multisystem inflammatory syndrome in children: is there a linkage to Kawasaki disease?. Trends Cardiovasc Med. 2020, 30:389-96. 10.1016/j.tcm.2020.07.004

5. Verdoni L, Mazza A, Gervasoni A, et al.: An outbreak of severe Kawasaki-like disease at the Italian epicentre of the SARS-CoV-2 epidemic: an observational cohort study. Lancet. 2020, 395:1771-8. 10.1016/S01406736(20)31103-X

6. Matsubara D, Kauffman HL, Wang Y, et al.: Echocardiographic findings in pediatric multisystem inflammatory syndrome associated with COVID-19 in the United States. J Am Coll Cardiol. 2020, 76:194761. 10.1016/j.jacc.2020.08.056

7. Belhadjer Z, Méot M, Bajolle F, et al.: Acute heart failure in multisystem inflammatory syndrome in children in the context of global SARS-CoV-2 Pandemic. Circulation. 2020, 142:429-36. 10.1161/CIRCULATIONAHA.120.048360

8. Health advisory: pediatric multi-system Inflammatory syndrome potentially associated with coronavirus disease (COVID-19) in children. (2020). https://www.health.ny.gov/press/releases/2020/docs/2020-0506_covid19_pediatric_inflammatory_syndrome.pdf.

9. CDC. Information for healthcare providers about multisystem inflammatory syndrome in children (MIS-C) . (2021). https://www.cdc.gov/mis-c/hcp/index.html.

10. CDC. Health department-reported cases of multisystem inflammatory syndrome in children (MIS-C) in the United States. (2021). https://www.cdc.gov/mis/cases/index.html. 